\title{
NOTICIAS SOBRE LA ALCAICERÍA DE LA SEDA DE SEVILLA Y SU TRANSFORMACIÓN EN EL SIGLO XVIII
}

\author{
POR JuAN CARlos HeRnándeZ NúÑEZ
}

\begin{abstract}
A lo largo del siglo XVII, el Ayuntamiento sevillano emprendió una serie de mejoras urbanas que afectarán a diferentes zonas de la ciudad. Una de estas obras es la remodelación de la Alcaicería de la Seda, sector que durante la última centuria había perdido su primitivo uso cormercial.

All during the 18th century the Sevilla town hall started a series of urban renewals that affected different parts of the city. One of these renewals was accomplished in the Alcaicería de la Seda, which was an urban section that during the 17th century had lost it's commercial sense.
\end{abstract}

A comienzos del siglo XVIII, la ciudad de Sevilla, la más fructífera y rica de toda España durante el quinientos, se hallaba inmersa en un período de larga y triste decadencia. A la crisis económica que padecía el país desde la centuria anterior, habría que añadir, para el caso sevillano, los estragos que causaron las epidemias, sequías e inundaciones sufridas por la ciudad en la segunda mitad del seiscientos. El comienzo del nuevo siglo no pudo ser más penoso, pués, sin haberse repuesto aún de las consecuencias de la Guerra de Sucesión, en 1717 fueron trasladados a Cádiz la Casa de Contratación y el Consulado Marítimo, perdiendo, por tanto, las instituciones promotoras de su pasada fortuna y las bases de su posible resurgimiento.

Una de las actividades más afectadas por la crisis fue el comercio y, en especial, el dedicado a géneros de gran valor o de lujo. Reflejo y consecuencia de este declive será la profunda transformación urbana que sufrí en el siglo XVIII, el sector donde tradicionalmente se había ejercido esta actividad, la Alcaicería de la Seda.

Pero, antes de analizar el proceso de remodelación que sufre la zona aludida, es necesario efectuar algunas precisiones sobre el sector urbano que durante el setecientos era designado como Alcaicería de la Seda. Bajo tal denominación se englobaba una amplia área dedicada al comercio, cuyos límites eran la calle Génova a poniente, la Plaza de San Francisco al norte, las calles Mercaderes-Escobas a levante y el sector septentrional de las Gradas de la Catedral, por su flanco sur. Aquí se encontraba localizado el edificio en el que se comercializaba desde época islámica 
dicho producto y que dió origen del nombre con que se conoció dicha zona ${ }^{1}$. Esta floreciente actividad había ocasionado que, en torno al mismo, se aglutinaran gran cantidad de negocios de mercancias relacionadas o derivadas de la seda, o vinculadas a otros materiales igualmente valiosos, como la plata. Estos se multiplicaron y diversificaron, especialmente tras el inicio del comercio americano. De ello se hizo eco Morgado al señalar la "suma riqueza de la alcaicería, o Alcaicería del oro, y Plata, Perlas, Cristal, Piedras Preciosas, Esmalte, coral, sedas, Brocados, Telas riquisimas, toda Sederia y Paños muy finos" 2 . Dichos productos se comercializaban en zonas diferentes, denominadas cada una de ellas por el nombre del arte al que se dedicaban, tal y como se indica en el padrón de armas de 1691, en el que se citan la "Alcaicería de la Seda, Sitio de los Pañeros, Platería de la plaza y de mazonería, etc" $^{3}$. Cada uno de estos lugares estaba perfectamente definido y delimitado.

La Alcaicería de la Seda había sido construida en 1196, por el califa Yacub Yusuf, frente a la puerta principal de la mezquita aljama, siendo un edificio de gran solidez y del "mejor estilo dentro de las de su clase, (obra) extraordinaria y maravillosa para aquel tiempo". Para ello fue necesario derribar "las casas, tiendas y las viejas alhondigas" de la antigua Azueyca o "zoco chico del clavo" ${ }^{4}$

Gracias a las referencias existentes en la bibliografía clásica, a la documentación gráfica y a los fragmentos de calles y callejas que aún se conservan, se puede realizar la reconstrucción, al menos en planta, del conjunto antes de su derribo ${ }^{5}$. La Alcaicería presentaba esquema casi rectangular, organizándose en

1. Las alcaicerías islámicas eran recintos comerciales donde se colocaban tiendas, talleres y almacenes, dispuestos a lo largo de una calle que podía estar porticada. También, se podían distribuir en torno a una plaza, o ser un conjunto de calles y callejuelas. De cualquier forma, eran sitios cerrados con puertas que se abrían a primera hora de la mañana y se cerraban por las noches, permaneciendo así, los días de fiestas. Normalmente, no existían viviendas en su interior, a no ser la del guarda. En ellas se vendían la seda cruda o en rama y productos de alto valor o de lujo. Se construían siempre, como en el caso de Sevilla o Granada, cerca de la mezquita mayor. Véase: TORRES BALBAS, Leopoldo: Ciudades Hispanomusulmanas. Reed. Madrid, 1985. Del mismo autor: "Alcaicerías". AlAndalus. V. XIV. 1949.

2. MORGADO, Alonso: Historia de Sevilla. Sevilla, 1587. Págs. 167-168.

3. MONTOTO, Santiago: Las calles de Sevilla. Sevilla, 1940. Pág. 252.

4. Véase, BOSCH VILA, Jacinto: La Sevilla islámica. 712-1248. Sevilla, 1984. Pág. 292-295.

5. Son muchas las refencias sobre la Alcaicería de la Seda en las obras de autores como Montoto, Morgado, Morales Padrón, etc. Sin embargo, los que la han estudiado con mayor detenimiento, además de las obras ya citadas de TORRES BALBAS y BOSCH VILA, son DOMINGUEZ ORTIZ, ANTONIO: "La alcaicería de la Seda de Sevilla en 1679". Sociedad y mentalidad en la Sevilla del antiguo régimen. Sevilla, 1993. Una reconstrucción de la misma, con la que no estamos de acuerdo, y un estudio de las relaciones existentes entre éste edificio y la mezquita mayor han sido realizados por TRILLO DE LEYVA, Juan Luis: Sevilla: La fragmentación de la manzana. Sevilla, 1991. Págs. 73-102. Así mismo, del recinto de la Alcaicería, siguiendo el nombre de las calles que la formaron, existen distintas referencias en: COLLANTES DE TERAN SANCHEZ, Antonio et alii: Diccionario histórico de las calles de Sevilla. Sevilla, 1993. Tomo I: págs. 56-57, 79-80, 161-163, 229-237, 362, 427-428. Tomo II: págs. 194, 267. En cuanto a la documentación gráfica en la que queda recojido dicho sector urbano habría que citar la edición realizada por el Ayuntamiento: Planos de Sevilla. Colección histórica. (1771-1918). Sevilla, 1992. 
torno a un eje mayor norte-sur, -el actual primer tramo de la calle Hernando Colóny dos vías secundarias que, en recodo, nacían y morían en dicho eje. Dichas calles siguen existiendo actualmente. La de poniente está convertida en un adarve en forma de "L", presentando su acceso, cerrado por una reja, en el inmueble número 38 de la calle Hernando Colón, bajo un soportal con columnas. Dicha calle aparece representada en los planos de la ciudad con la misma forma que hoy tiene, desde 1870 , fecha en la que fue realizado el plano de Sevilla por el Cuerpo del Estado Mayor del Ejército. La vía frontera tiene inicio en el número 23 de la misma calle. Cerrada por una puerta, se ha convertido en un patio interior, también en forma de "L", del actual restaurante "Casa-Robles". Continúa por detrás de éste, así como por el resto de inmuebles, que tienen su acceso por la calle Alvarez Quintero, hasta el Restaurante denominado "Las Escobas". Dicho tramo de calle ha sido siempre representado integro, en forma de " $\mathrm{C}$ " invertida, en los planos de la ciudad desde 1771 hasta 1848, ya que en la planimetría posterior dicha calle quedó embutida dentro del conjunto de casas que formaban la manzana.

El conjunto de la Alcaicería tenía dos accesos principales, correspondientes a sus lados menores, formados por arcos que recibían el nombre de Tundidores, el situado al norte, y de la Rosa, el del sur. Presentaba, a la vez, dos postiguillos en los laterales que, por medio de callejuelas, unían las vías secundarias con las calles Batihojas y Escobas. De ellas, la que salía a Escobas tradicionalmente se denominó de Espantaperros, apareciendo representada en los planos de la ciudad, hasta el de 1848. En la planimetría posterior quedó recogida la transformación que sufrió el ángulo sureste de la Alcaicería, al ser derribado su volumen saliente y formada la unión de las actuales calles Alvarez Quintero y Alemanes en un ángulo recto, tal y como hoy continúa. A estos accesos, conocidos por la bibliografía clásica, habría que añadir, al menos, dos postiguillos más. Uno en la calle Alemanes y otro en la calle Florentín. Bajo los soportales de aquella, actualmente existe, entre un negocio de prensa y el "Bar Gonzalo", un pasaje cerrado por una verja, que dá acceso a un pequeño adarve el cual aún sigue siendo de uso público, ya que en él se encuentran las puertas a los inmuebles numerados con el 15,17 y 19 de esa calle. Es el correspondiente al número 17 , una estrecha casa con fachada de menos de 2 metros de ancho, la que posiblemente taponaría el acceso a la calle secundaria de levante. En este mismo sentido, habría que aludir a la casa 18 de la calle Hernando Colón, sede de "Seguros Previsión Financiera", que presenta un pasillo y puerta de servicio a la calle Florentín, siendo ésta prácticamente del mismo ancho que la calle secundaria de poniente. Además, en los planos de la ciudad desde 1771 aparece en este sector, un pequeñísimo adarve que podría coincidir con la prolongación de la calle secundaria que, en estos planos, no aparece representada. Tanto éstos accesos secundarios como los principales se cerraban con puertas, que estaban al cuidado del Guarda de la Alcaicería, quien tenía su vivienda sobre el Arco de la Rosa. 
La Alcaicería de la Seda se encontraba unida a la plaza de San Francisco por la calle Tundidores, correspondiente al actual segundo tramo de la calle Hernando Colón. En dicha vía, en la acera de los pares, estaban asentados los negocios del arte que le daban nombre a la calle, mientras que en el lado de los impares se encontraban los mercaderes de paño a vara ${ }^{6}$. Al final de la misma, delante de la Alcaicería, existía un ensanche denominado plazuela de los Alfayates, por los artesanos que en ella tenían sus negocios. Esta comunicaba con la calle Batihojas, hoy Cabo Noval, por medio de la calleja aún denominada Florentín, y por otra que recibía el mismo nombre que la citada plaza -actualmente denominada Rodríguez Zapata- con las calles Mercaderes-Escobas, la actual Alvarez Quintero.

El lugar denominado como "Platería de la Plaza" o, según Morgado, Alcaicería del Oro y Plata, no era en realidad un edificio cerrado y construido para éste fin, como el ya comentado para la seda. Por el contrario, se trataba de una calle que unía la plaza de San Francisco con las Gradas del frente norte del Patio de los Naranjos y que, en uno de sus tramos, se ensanchaba formando una plazoleta. Dicha calle -actualmente Cabo Noval- era conocida con el nombre de Batehojas o Batihojas, "llamada así porque en ella se fabricaban los panes o láminas finísimas de oro utilizadas en los trabajos de dorado" 7 . Esta se comunicaba con la Alcaicería de la Seda, por medio de un callejón y un postiguillo ${ }^{8}$. Así mismo, como se señala en el plano de la ciudad levantado por orden del Asistente Olavide en 1771, la calle Batihojas tenía una salida a las Gradas y dos a Génova. De las últimas, sólo se conserva la actualmente denominada Felipe Pérez. Tanto las comunicaciones con las Gradas y la segunda vía con Génova, -hoy inexistentes-, posiblemente no fueran auténticas calles, sino unos tránsitos abiertos bajo las casas allí existentes. Sin embargo, el autor del plano los interpretó como verdaderas calles, posiblemente al estar más interesado en representar las vías de comunicación existentes en esta parte de la ciudad, que en plasmar los auténticos espacios abiertos correspondientes a las calles. Esta misma libertad se repití al dibujar la calle Alcaicería de la Seda, donde no aparecen los dos arcos que la cerraban, o en la Plaza del Arzobispo, donde tampoco figuran la Puerta de Palos y el Arco de Santa Marta. Con seguridad, los accesos a la calle Batehojas, al igual que sucedía con la Alcaicería, se cerrarían por las noches. De éstos, solo se han localizado referencias al postiguillo de comunicación con la Alcaicería y a la puerta de las gradas, sobre la que será construída una capilla, en 1762, por el gremio de los plateros a la Purísima Concepción ${ }^{9}$.

La fisonomía que presentaban las calles de este sector no podría ser muy diferente a la que tenían las propias vías de la Alcaicería. En ésta, las construcciones,

6. DOMINGUEZ ORTIZ, Antonio: Ob. cit. Pág. 55.

7. Idem. Pág. 56.

8. Archivo Municipal de Sevilla. (A.M.S.). Sección 5. Tomo 6. Núm. 24.

9. A.M.S. Sección 5. Tomo 43. Núm. 17. 
habitualmente, debían ser bajas, posiblemente de una o dos plantas, utilizando la superior de almacén o excepcionalmente como vivienda, mientras que la inferior servía de tienda. Dichas edificaciones eran muy pequeñas y estaban precedidas de soportales donde se exponía la mercancia en mesas, bancos o poyetes ${ }^{10}$. De igual manera se hallaba configurado el tramo de Tundidores, al menos en el siglo XVII, pues estaba "formado por una serie de tiendas bajo soportales, que, al menos en la acera de los impares, presentaban entrantes o rinconeras" 11 .

Si bien la actividad comercial desarrollada en este sector urbano había tenido una época de gran esplendor en los siglos XV y XVI, en las postrimerías del seiscientos se encontraba completamente deprimida y en ruina gran parte de sus edificios. Las causas posiblemente habría que buscarlas en las leyes dictadas por el gobierno para paliar la crisis y, en particular, las pragmáticas promulgadas contra el uso de los objetos de lujo, como los tejidos de seda y brocados. Consecuencia de ellas fueron los "seiscientos tiradores de oro, doradores y pasamaneros" que en 1648 se quedaron sin trabajo ${ }^{12}$. La situación no cambió mucho en fechas posteriores y así, en 1679, al llevarse a cabo el reconocimiento de las tiendas existentes en la Alcaicería y en sus inmediaciones, ordenada por el Consejo de Castilla, se comprobó que la mayoría de los negocios habían cerrado y que en algunos de los que aún permanecían abiertos, ya no se vendía seda. Así mismo, se advierte en dicho reconocimiento que algunas edificaciones se habían destinado a otros fines, como el de vivienda -se citan siete-, a talleres de satres e, incluso, a cuadras ${ }^{13}$.

A lo largo del XVIII, el progresivo abandono de la actividad comercial y la cercanía de los centros político y religioso de la ciudad, hizo que el sector se convirtiera en núcleo residencial. En 1724, algunas de sus viviendas no sólo tenían puertas a la Alcaicería de la Seda, sino también a la calle Batihojas, mientras las casas en ella existentes presentaban un segundo acceso a la calle Génova ${ }^{14}$. Posiblemente, con este cambio de uso haya que relacionar las noticias sobre las obras realizadas en 1722 , aunque al no existir ninguna otra información posterior resulte imposible saber la razón e intención de tales intervenciones. En una de ellas el Ayuntamiento de la ciudad solicitó al Cabildo de la Catedral que derribase los portales de la Alcaicería de la Seda -el Cabildo tenía cinco tiendas-,

10. Idem. Págs. 57-58. Véase, así mismo, COLLANTES DE TERAN SANCHEZ, Antonio: Sevilla en la Baja Edad Media. La ciudad y sus hombres. Sevilla, 1977. Págs. 129-130.

11. COLLANTES DE TERAN SANCHEZ, Antonio et alii: Ob. cit. Tomo I. Pág. 427.

12. Véase para este tema, DOMINGUEZ ORTIZ, Antonio: Orto y Ocaso de Sevilla. $2^{2}$. ed. Sevilla, 1974. Págs.116-152.

13. DOMINGUEZ ORTIZ, Antonio: "La alcaicería ...". Págs. 55-67.

14. La información procede de un pleito que ponen algunos vecinos, residentes en el interior de la Alcaicería, contra el portero de la misma. Este al cerrar las puertas del edificio impedía la entrada o salida a los primeros. A.M.S. Escribanía 5. Carpeta 6, núm. 24. 
operación que el maestro mayor del Ayuntamiento evaluó en 3000 reales ${ }^{15}$. La otra es una carta que los capitulares eclesiásticos dirigieron al Ayuntamiento solicitando designase a una persona que fijara "las medidas para los simientos de unos pilares en una de las tiendas de la Alcaiceria de la Seda" ${ }^{16}$. Este tipo de obras de poca envergadura, que se seguirán realizando a lo largo de la centuria, pudieron ser, en algunos casos, motivo de cierta picaresca. Así, Josefa de Barcena solicitó en 1775, permiso al Ayuntamiento para sanear el soportal que tenía su vivienda, aprovechando la licencia para construir en su lugar "un quarto de cassa", quitando "lo diafano de la calle" ${ }^{17}$.

Si bien estas noticias reflejan la transformación que se efectuó en el sector, no es menos significativa la referente a la protesta que eleva uno de sus vecinos al Ayuntamiento a consecuencia de la utilización de una antigua capilla por vagabundos. Dicha capilla había sido construida en 1738 por los plateros, sobre un gran arco que servía de puerta al final de la calle Batihojas, dedicándola a la advocación de la Purísima Concepción. Sin embargo, veinticuatro años después, en 1762, la capilla había sido abandonada, su imagen trasladada "al altar de San Elixio (...), quedando todo el sitio y fabrica amenasando prosima ruina, asi a la dicha pared como a las ymmediatas", y sirviendo de "guarida" a "malehechores" (sic) ${ }^{18}$.

De cualquier forma y a pesar de las obras efectuadas en la primera mitad del setecientos, la estructura básica de la Alcaicería no cambiaría, pues en el ya aludido plano de Olavide el sector continúa presentando forma rectangular, siendo sus límites las mismas calles que en los siglos precedentes. Cuando realmente va a transformarse el espacio interno de la zona es a partir de 1778, al ensancharse sus calles principales y al levantarse en ella una serie de nuevas edificaciones. De estas obras, que van a durar más de diez años, no ha sido posible localizar los planos, aunque los documentos hacen continua referencia a ellos.

El 20 de mayo de 1778 se presentó a la ciudad un escrito redactado por el Procurador Mayor, en el que se proponía hacer transitable la Alcaicería a los coches ${ }^{19}$. Basaba su petición en que al ser la Alcaicería paso directo desde la Plaza de San Francisco a la Catedral, era la única vía altemativa a la Calle Génova que, debido a su contínuo tránsito, era necesario cerrarla, por "lo menos 2 veces al año", para empedrarla, con el consiguiente trastorno para el público. Pero, para hacer viable el paso de carruajes a través del edificio de la Alcaicería, era imprescindible realizar varias transformaciones. La primera intervención consistiría en solucionar los inconvenientes derivados de la presencia del Arco de la

15. Archivo Catedral de Sevilla. (A.C.S.). Autos Capitulares. Año de 1722. Fol.46.

16. La persona designada por el Ayuntamiento fue el Veinticuatro de la Ciudad, don Diego Rodríguez de Rivera. A.M.S. Actas Capitulares. Años de 1722-1723. Escribanía 2. Tomo 113.

17. A.M.S. Sección 5. Tomo 266. Núm. 5.

18. A.M.S. Sección 5. Tomo 43. Núm. 17.

19. En ese momento el cargo de procurador Mayor era ejercido por José de los Ríos, Veinticuatro de la Ciudad. A.M.S. Actas Capitulares. Años de 1777-1778. Escribanía 2. Tomo 112. 
Rosa, a la entrada del recinto ${ }^{20}$. Para solucionarlos, se presentó una doble alternativa, peraltarlo o eliminarlo, construyéndolo en otro lugar "con igual decencia". Esta última opción era debida a que en el mismo existía un retablo con la imagen de la Inmaculada, cuya devoción se debía conservar por "bien público". La segunda actuación, localizada en el extremo contrario del recinto, consistiría en eliminar "los colgadizos de tablas en que hacen casas de madera dos individuos", quienes ocupaban el espacio público estrechándolo considerablemente. Una tercera se destinaría a impedir que diariamente se organizasen tenderetes aprovechando los soportales, los cuales no producían renta alguna, afeaban el lugar y entorpecían el paso hacia los inmuebles situados tras los pórticos. Estos eran en su mayoría propiedad de la Cartuja de las Cuevas o de la Catedral, según se indicaba en los azulejos situados en sus fachadas. Todas estas operaciones tenían como finalidad crear una nueva calle "de mucha hermosura (...) y mayor comodidad". Leida y discutida la propuesta, el Ayuntamiento decidió ponerla en práctica, por lo que encargó al Procurador Mayor realizar "las diligencias judiciales y extrajudiciales que combengan sobre averiguar a quien" pertenecían tales tenderetes.

El 3 de agosto, todos los problemas estaban resueltos ${ }^{21}$. El Ayuntamiento aprobó que la obra del Arco de la Alcaicería pasase a la Junta Municipal "para que probidencie lo conveniente a que se ejecute la obra que sea necesaria", teniendo en cuenta que el retablo de dicho arco se tendría que dejar en el mismo lugar "para que no se pierda la devoción de los fieles". Asimismo, se acordó demoler la obra realizada por Josefa Barcena antes citada, consistente en convertir en vivienda unos soportales, y mandar oficios a los propietarios de los tinglados para que los quitasen.

El 12 de ese mes, el Cabildo de la Catedral se reunió para leer la carta del Procurador Mayor, informando de las obras proyectadas. En dicha comunicación se especificaba que a los muros de los edificios pertenecientes a la Catedral, sobre los que apoyaban los soportales, "no se les causaría el menor perjuicio, pues quedarian reparados los huecos, que descubriesen las vigas de los colgadizos que se sacasen" 22 . Sin embargo, once días más tarde, el Cabildo conoció extraoficialmente que no era esa la única obra proyectada por el Ayuntamiento, pues, muy al contrario, era el inicio de un proyecto de mayor envergadura ${ }^{23}$. Con

20. Los documentos sólo se refieren al Arco de la Rosa no haciendo ninguna mención al de Tundidores. Aunque no se tienen referencias, posiblemente ello sea debido a que en 1721 , al construirse sobre éste la capilla dedicada a Nuestra Señora de la Concepción, se le dotara de mayor amplitud. A.M.S. Sección 5. Tomo 278. Núm. 12.

21. Nuevamente será José de los Ríos el encargado de realizar las diversas negociaciones de los derribos y en especial en mandar demoler la casa construida por Josefa de la Barcena, viuda de Francisco Ordóñez. A.C.S. Actas Capitulares. Años de 1777-1778. Escribanía 2. Tomo 113.

22. En dicha carta, fechada el 4 de agosto de 1778, se informaba que el Arco de la Seda "se havia ordenado levantar". A.C.S. Autos Capitulares. Año de 1778. Fols. 274-275.

23. El secretario informaba que un Señor, sin especificar su nombre, le había comunicado que el Ayuntamiento pretendía crear dos nuevas calles. A.C.S. Autos Capitulares. Año de 1778. Fols. 332 vto.-333. 
objeto de conocer con exactitud las intenciones del Ayuntamiento, el Cabildo comisionó a los responsables de Casas y a la Diputación de Negocios. Estos presentaron su informe el 2 de octubre basándose en las indicaciones del propio maestro mayor de la Ciudad ${ }^{24}$. Según éste, el Ayuntamiento pretendía abrir dos vías alternativas a la calle Génova, la de Batihojas y la de la Alcaicería. En la primera, que quedaría "transitable de coches hasta el sitio de las Gradas de esta Santa Iglesia", se debían demoler unas casas humildes pertenecientes a la Catedral, compensándose a dicha institución "con mayores ventajas". Pero, al ser este un proyecto aún sin aprobar por parte del Ayuntamiento, no se le había notificado al Cabildo. A pesar de ello, en previsión de una posible oposición del Cabildo Catedral en el caso de realizarse, ya se le comunicó que "la Ciudad se hallaba autorizada con la instrucción de Intendentes, y la última Real Provisión de S.M. y Señores de su Consejo de Castilla para hermosear los Aspectos públicos, y quitar las deformidades de sus calles, y evitar los pecados, que se cometian en sitios inmundos y reservados". En lo referente a la segunda calle, la de la Alcaicería, dicha Diputación no encontraba posible oposición al proyecto de la Ciudad, sobre todo cuando ésta tenía el respaldo de las órdenes llegadas de Madrid. A éste respecto, se leyó otra comunicación del Procurador Mayor en la que indicaba haberse comenzado la obra, quitándose el retablo del arco. Así mismo, señalaba que se estaba'derribando la vivienda construida por Josefa de Barcena y que la Cartuja iba a proceder a demoler los soportales de sus propiedades. Ante ésta situación se solicitaba al Cabildo eclesiástico una rápida contestación. Este mandó que la Diputación de Negocios, con fecha de 27 de septiembre, diese el permiso oportuno para el derribo de los portales y para que, al mismo tiempo, se advirtiese que cuando la Ciudad pusiera en práctica sus nuevos proyectos, se tuviesen en consideración "las fincas, que pertenezcan a sus Dotaciones, para que en la execucion de ellos, no se les infrinja, o cause perjuicio alguno". En el informe anteriormente aludido se habla por primera vez de la existencia de un plano que recogía todas las transformaciones que iba a sufrir el sector de la Alcaicería, pero éste, como ya se indicaba, no se ha podido localizar.

Todas estas operaciones son consecuencia de las órdenes llegadas desde Madrid el 30 de julio de 1761, destinadas al saneamiento y hermosura de la ciudad ${ }^{25}$. Debe tenerse presente que las mismas no se habían puesto en práctica hasta después de haberse comenzado el proyecto primitivo de la Alcaicería. Se desconoce la razón de la tardanza, sobre todo cuando el Procurador Mayor había ya propuesto a la ciudad, con fecha 20 de mayo, hacer una nueva calle, paralela a la de Génova, que sirviera para comunicar el Ayuntamiento y el centro económico y religioso, cuando aquella estuviese cerrada por reparación.

La calle Génova constituía el único enlace entre los centros económicos, militar y político de la ciudad, siendo una de las arterias más importantes de

24. A.C.S. Autos Capitulares. Año de 1778. Fols. 339 vto- 343.

25. A.C.S. Autos Capitulares. Año de 1778. Fols. 339 vto.-343. 
Sevilla desde el siglo XVI. Esto hacía que, a través de ella, existiese un permanente tráfico rodado, que su pavimento no era capaz de soportar indemne, teniendo por eso que repararse continuamente. Su pavimentación, heredada de los últimos años del siglo XVI y que se seguirá utilizando en el siglo XVIII, estaba formada por cantos extendidos y apisonados sobre un lecho de tierra ${ }^{26}$. Evidentemente, no era una técnica muy resistente, por lo que se procedió a solucionar el problema ofreciendo como alternativa la construcción de otra vía que descongestionara el tráfico y con la que se evitaría, no sólo la incomunicación de dichos centros durante las obras de reparación, sino también el contínuo gasto en pavimentación de la primera, una vez que se redujese su uso. Por tanto, la intención de la apertura de la calle Alcaicería no era simplemente una cuestión de utilidad, sino también de ahorro. Pero, poco tiempo después y basándose en las nuevas Ordenanzas, se plantearía una remodelación de todo el sector, ya que al haber perdido su función económica inicial, se había convertido en un centro improductivo para la ciudad, ocupado por diversas viviendas, sin ningún orden o plan preestablecido, y sirviendo de punto de reunión a gentes de mal vivir que provocaban continuos escándalos y alborotos. Con el nuevo proyecto, la Ciudad pretendía hacer de dominio público la zona de la Alcicería, transformándola en un espacio abierto y transitable por medio de una nueva alineación de sus calles $\mathrm{y}$, como consecuencia de ésta, una nueva distribución y disposición de los edificios de viviendas.

El 30 de octubre de 1778 el Ayuntamiento acordó aprobar las obras realizadas hasta ese momento en la Alcaicería, así como el reparto que se había hecho del espacio de ella, distinguiendo entre el que entonces se hacía público y el que iba a ser edificado ${ }^{27}$.

El 9 de noviembre fue el Cabildo religioso el que aprobó dicho plan, al ceder a la Ciudad 90 varas que ocupaban ciertas casas de su posesión, necesarias para realizar la apertura a las Gradas de la calle Batihojas ${ }^{28}$. En compensación, la Ciudad ofreció a la Catedral "setescientos setenta y nueve varas de sitio publico" que se encontraban junto a otras posesiones del Cabildo, recomendándose que en dicho lugar se edificasen seis casas. Tres tendrían su portada en dicha calle Batihojas y las otras tres en la de la Alcaicería. Todas ellas irían unificadas por su fachada. En el caso de que el Cabildo no tuviese dinero suficiente, o no

26. MARIN DE TERAN, Luis y POZO SERRANO, Aurelio del: Los pavimentos. Un fragmento de la historia urbana de Sevilla. Sevilla. 1985. Págs. 42-43. Prácticamente este tipo de empedrado se seguirá utilizando, aunque mejorada su realización según se desprende del "Reglamento de empedrado de 1773", hasta 1787. En esta fecha se experimenta por primera vez en Sevilla y en la calle Génova el "embaldosado", posiblemente con losas de Tarifa según se desprende de documentos posteriores, y que tanto éxito había tenido en las ciudades de Madrid, Cádiz y Barcelona. A.M.S. Sección 5. Tomo 98. Núm. 2 y 3.

27. El encargado de verificar las obras era Juan Antonio de Santamaría, asistente interino de la ciudad. A.M.S. Actas Capitulares. Años de 1776-1778. Escribanía 1. Tomo 58.

28. A.C.S. Autos Capitulares. Año de 1778. Fols. 391-397. 
quisiese edificarlas, las podría vender. Era obvio que el Cabildo eclesiástico aceptase dicha proposición, pués sus posesiones se incrementaban considerable y gratuitamente, por ceder tan sólo las 90 varas ocupadas por unas humildes casas. Ante ésto, el Cabildo dió las gracias "por esta su particular atención" de la Ciudad. Las calles a realizar, según dicho informe, tendrían casi 6 metros de ancho la de la Alcaicería y 5 la de Batihojas.

La última noticia referente a la formación de estas calles, corresponde al momento en que se acordó quitar tres columnas de un soportal que entorpecían el paso público a la salida de la Alcaicería de la Seda ${ }^{29}$. Estas pertenecían a "un Patronato que administraba el Hospital de San Juan de Dios". En el acta capitular del 18 de noviembre de 1778 , se hace referencia a que la Alcaicería "se a ensanchando para uso de los Coches". Esto haría suponer que las obras de dicha calle ya estaban finalizadas.

Sin embargo, la calle Batihojas no será terminada, ya que diez años más tarde, en 1788, todavía se seguía trabajando en ella y en la construcción de algunas de sus viviendas ${ }^{30}$. En ese año, aún faltaban por construirse catorce casas, además de completar la "salida a la calle de los Batihojas a las Gradas de la Iglesia Maior". Para diez de dichas casas se tenía quien las construyera "sujetandose alas medidas y reglas convenientes que ya estaban dictadas guardando conformidad para el mejor aspecto publico". Pero para las cuatro restantes, que ocupaban los terrenos pertenecientes al Conde de la Torre y al Marqués de Guillena, no había quien se encargara de edificarlas. A estas se les había incorporado un callejón, que comunicaba la calle Génova con la de Batihojas, origen de un grave conflicto que paralizaría las obras durante dos años.

Según se desprende de los informes, el Marqués de Santa Cruz se ofreció a labrarlas, incorporándose el citado callejón al comienzo de las obras. Tal operación no había sido autorizada por la Ciudad, por lo que el Ayuntamiento, al darse cuenta pidió se restituyera el callejón por "que tiene ya ottro destino, pues esta compreendido enlas mil trescientas y cincuenta varas de sittios publicos que serrepartieron entre edificios que sehan de labrar". Ante la negativa del Marqués y los graves problemas que acarreaba el incidente, para zanjar el conflicto, la Ciudad solicitó al Consejo de Castilla la licencia necesaria para que con los caudales públicos adquiriese las fincas, realizando ella misma las cuatro casas. Aquella será concedida, mandándosele los planos y las condiciones para dicha obra a Félix Caraza. Las obras saldrían a pregón el 27 de noviembre de $1789^{31}$.

La documentación no continúa, aunque debe suponerse que la obra sería terminada en cuanto a las viviendas. Sin embargo, no se especifica si se llegó a realizar la salida desde la calle Batihojas a las Gradas. No se tienen referencias

29. A.M.S. Actas Capitulares. Año de 1777-1778. Escribanía 2. Tomo 113.

30. Dichas noticias se encuentran recogidas en el A. M.S. Sección 12. Papeles Conde de la Mejorada. Tomo 3. Números 11, 20,53. Asimismo, Actas Capitulares. Años de 1778-1790. Escribanía 1. Tomo 62.

31. A.M.S. Actas Capitulares. Años de 1788-1790. Escribanía 1. Tomo 62. 
que expliquen este punto, ya que en los acuerdos capitulares de la Ciudad no consta ninguna noticia sobre el tema. A pesar de ello y como ya se había hecho mención anteriormente, en el plano de Olavide, realizado en 1771, siete años antes de comenzar la remodelación del sector, la calle Batihojas servía de enlace entre la Plaza de San Francisco y las Gradas. Esta comunicación entre ambos sectores de la ciudad va a continuar, por lo menos, hasta 1848 , fecha en la que se firma el plano de Herrera y Dávila. En el mismo aparece reflejada una profunda transformación en la calle, ya que ha desaparecido casi un treinta por ciento de la misma, siendo ocupado este espacio por viviendas. En éste porcentaje se incluye su primitivo ensanche o plazoleta y su prolongación y salida a Gradas, al igual que la calle de comunicación con Génova. En el citado plano de 1848, la calle Alcaicería, ya denominada de Colón, seguía presentando sus extremos abiertos, tal y como aparecía en el de $1771^{32}$. Sin embargo, no será hasta cuatro años más tarde, en 1852, cuando se comience el derribo de los arcos que la cerraban. El primero de ellos, el de la Rosa, caerá el 17 de enero de ese año, mientras que el de los Tundidores permanecerá en pié hasta $1854{ }^{33}$.

Durante la segunda mitad del siglo XIX y las primeras décadas de la centuria siguiente, se completaría la renovación de la manzana. En estas actuaciones desaparecerían, en la calle denominada desde 1892 Hernando Colón, el ensanche que había configurado la Plaza de los Alfayates y parte de las calles internas del edificio de la Alcaicería, que serán privatizadas. Al mismo tiempo desaparecieron los soportales, que fueron tan característicos de dicha manzana, al ser ampliadas las calles y modificados sus trazados, construyéndose edificios de nueva planta ${ }^{34}$.

Por todo lo dicho, se puede comprobar que la principal intervención en esta zona a lo largo del XVIII va a ser la apertura de la Alcaicería, tras la destrucción de su configuración medieval. Las razones de esta intervención, que originalmente eran de orden público, habrá que buscarlas en las Ordenanzas que procedentes de la Corte, impregnadas del espíritu de las reformas emprendidas por Carlos III, intentan configurar la ciudad de acuerdo con el ideal racionalista característico del Siglo de las Luces. La remodelación de la Alcaicería, pués, habría que incluirla dentro de un programa de mayor envergadura, emprendido por el Ayuntamiento, cuyo fin era el embellecimiento y mejora de la ciudad. Así, por estas fechas se

32. En 1845 será cambiado el nombre de la calle de Alcaicería de la Seda, por el de Colón, en menoria del bibliófilo Hernando Colón, siendo en 1892 cuando pase a llamarse con el nombre completo de Hernando Colón. MONTOTO, Santiago: Ob cit. Pág. 250.

33. El 20 de octubre de 1853, el Regidor Pedro González de Rasilla, había propuesto al Ayuntamiento el derribo del arco de los Tundidores. A pesar de que fue aprobada su demolición el 25 del mismo mes, ésta no será comenzada hasta el 18 de enero del año siguiente. Hemeroteca Municipal de Sevilla. El Porvenir. Años de 1852, 1853, 1854.

34. COLlaNTES DE TERAN SANCHEZ, Antonio et Alii: Ob. cit. Tomo I. Págs. 163, 427-28. 
realizaron los malecones en los barrancos del río, inmediato a los Humeros, el embellecimiento de sus orillas, las alamedas de la Puerta de Jerez y del Patín de las Damas, las reformas del puente de barcas, la construcción de los atajadizos en la plaza de la Alfalfa o los soportales en la del Pan, por citar algunas de las más significativas. Al mismo tiempo, se harían obras de infraestructura como eran limpieza, alumbrado público y empedrado de la ciudad ${ }^{35}$. Para éste último, el Ayuntamiento había dado unas nuevas Ordenanzas, sobre la forma de pavimentar las calles en $1773{ }^{36}$. Tales obras, producto de las Ordenanzas pretendían la higiene, la regularidad, la geometría de la ciudad y la comodidad y provecho de sus habitantes.

35. GUICHOT Y PARODY, Joaquin: Historia del Excmo. Ayuntamiento de la Muy Noble, Muy Leal, Muy Heróica é Invicta Ciudad de Sevilla. Tomo III. Sevilla, 1898. Págs. 114-119.

36. A.M.S. Sección 5. Tomo 98. Núm. 3. Véase también, Idem. Sección 11. Papeles Conde del Aguila. Tomo 33. Núm. 37. Asimismo, MARIN DE TERAN, Luis y POZO SERRANO, Aurelio del: Ob. cit. Págs. 31-48. 


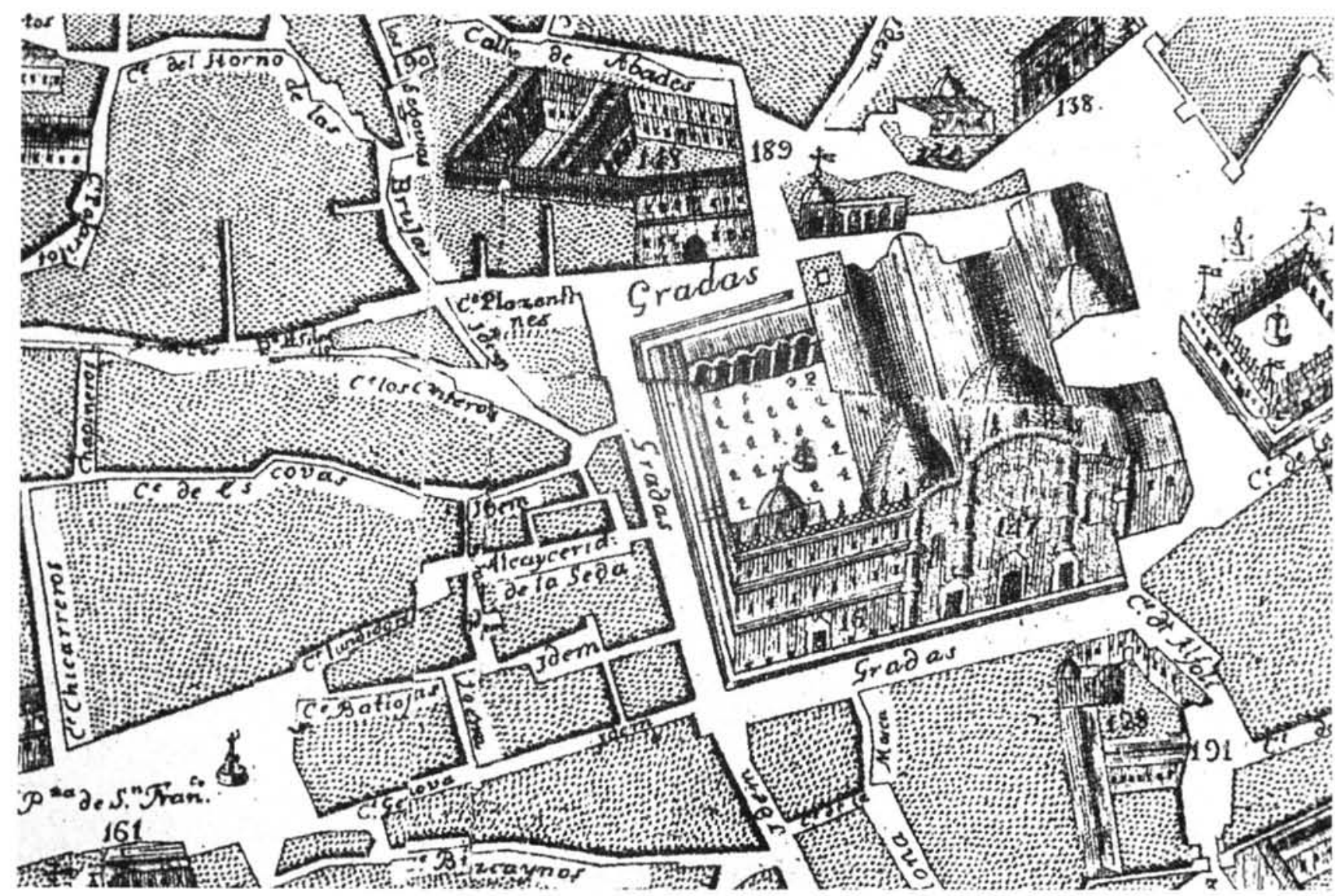

1.- "Plano topographico de la M.N. y M.L. Ciudad de Sevilla. Se levantó y se abrió por Disposición del Sr. D. Pablo de Olavide..., 1771". Detalle. 


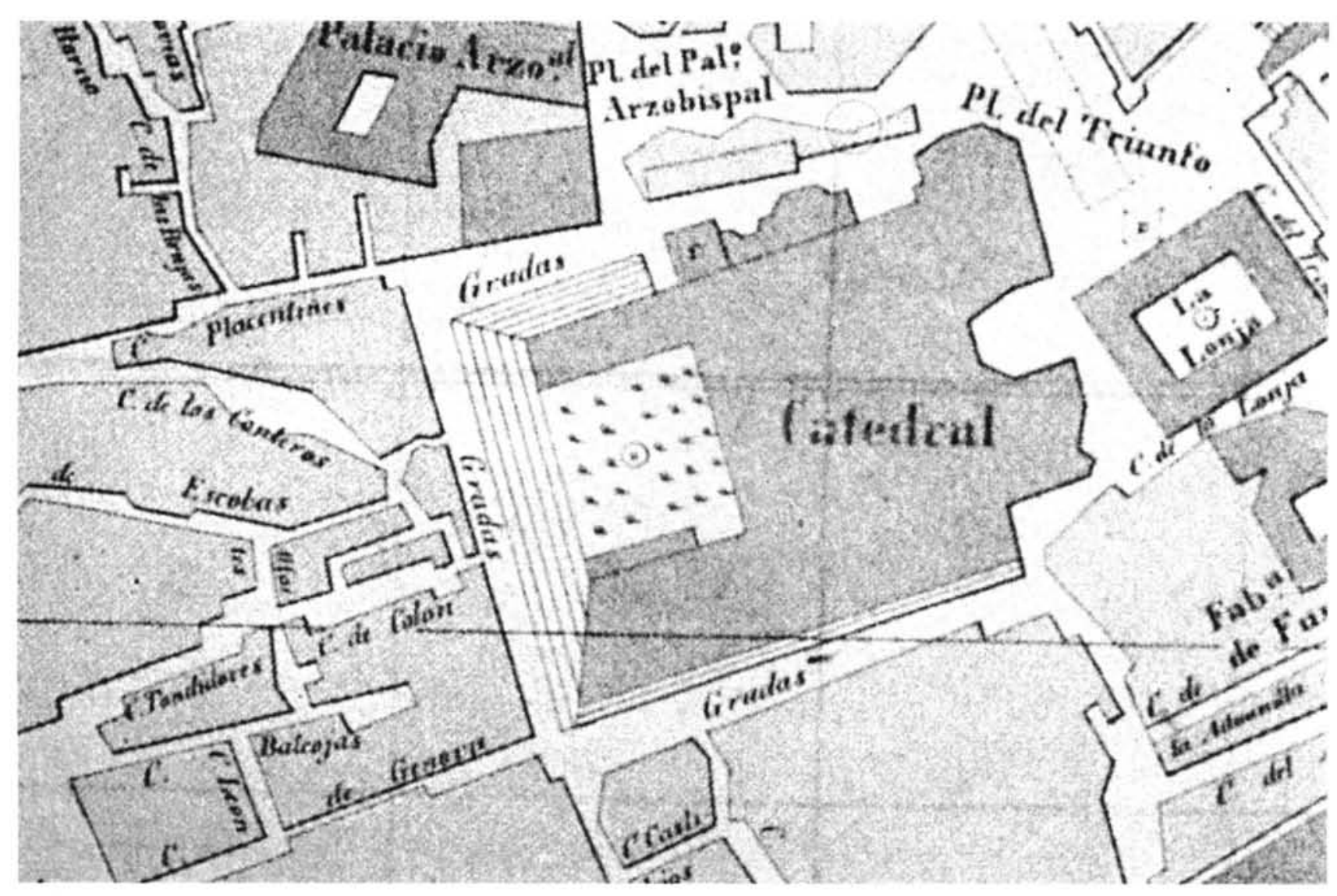

2.- "Plano de M.N., M.L., M.H. e I. Ciudad de Sevilla, con las mejoras hechas hasta 1848...". Detalle. 


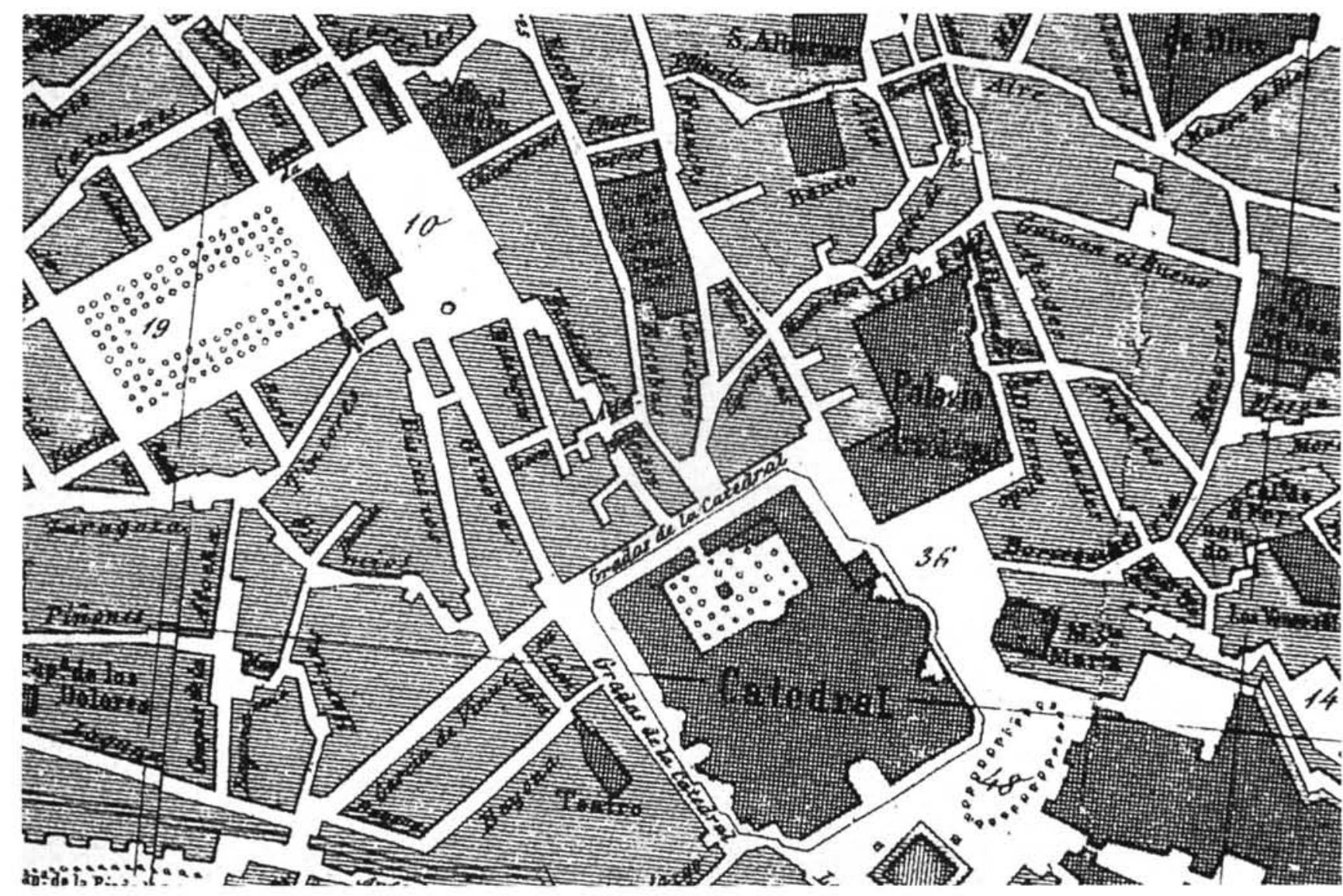

3.- Plano de Sevilla, por D. Manuel Alvarez-Benavides y López, dedicado a la Excma. Diputación Provincial por su editor D. Carlos Santigosa. Año 1868". Detalle. 


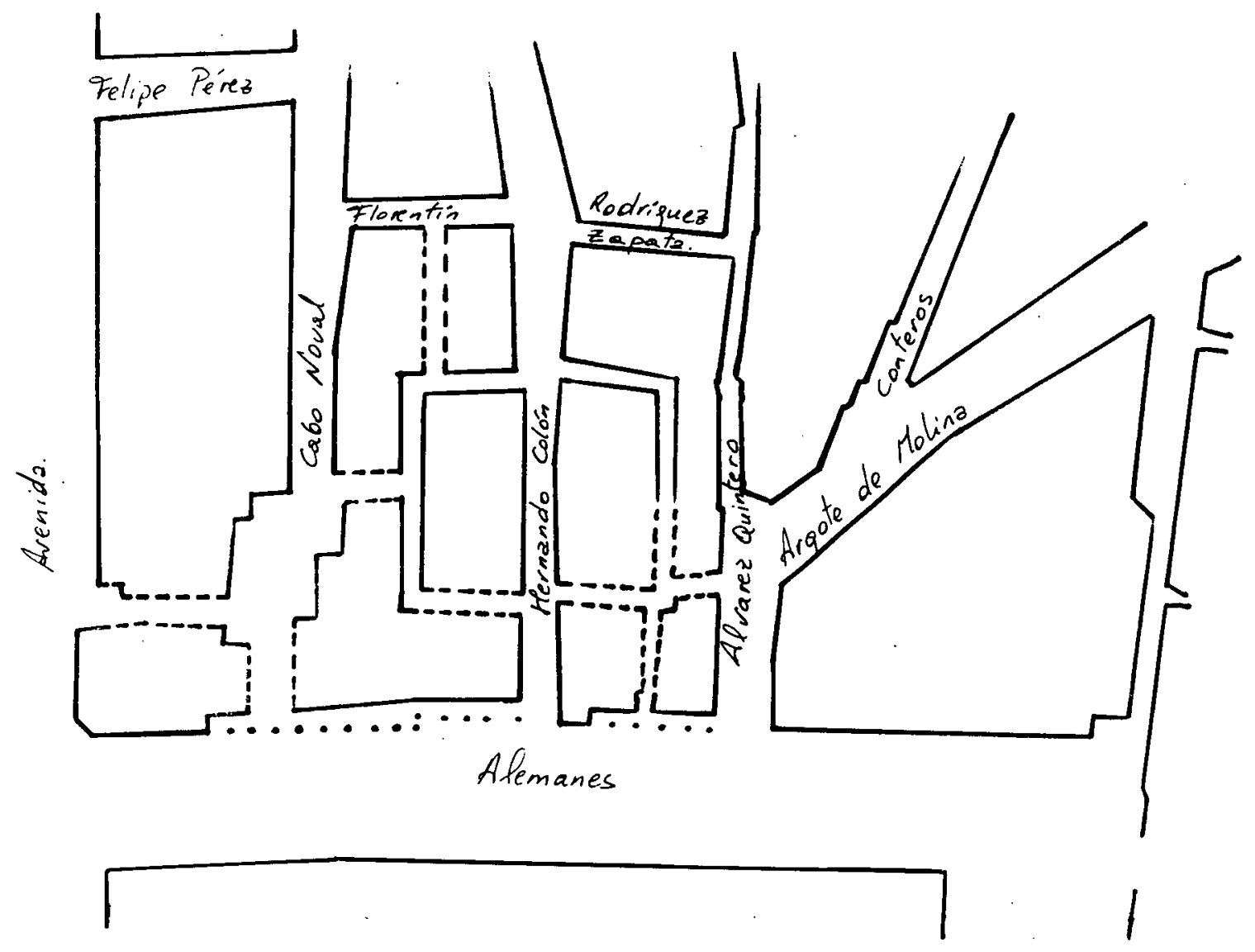

4.- Reconstrucción hipotética del edificio de la Alcaicería de la Seda. 